\title{
A Finite Element Study of The Elastic Properties of a Cracked Cellular Structure with Trapezoidal Beams
}

\author{
Jiong Zhang ${ }^{1}$, Weidong Liu² and Liankun Wang1* \\ ${ }^{1}$ School of Civil Engineering and Architecture, Wuyi University, PR China \\ ${ }^{2}$ College of Energy and Electrical Engineering, Hohai University, PR China
}

*Corresponding author: Liankun Wang, School of Civil Engineering and Architecture,

Received Date: June 22, 2019

Wuyi University, No. 22 Dongcheng village, Jiangmen 529020, PR China.

Published Date: June 24, 2019

\begin{abstract}
The elastic properties of a cracked cellular structure of close-to-zero Poisson's ratio with trapezoidal beams are studied by the finite element method in this paper. The effects of the crack length and crack angle on the non-dimensional equivalent modulus, including elastic moduli in the $\mathrm{x}$-direction, $\mathrm{y}$-direction, and the shear moduli are analyzed. The numerical results indicate that the degree of reduction in the non-dimensional equivalent modulus due to the crack depends on the crack angle and length.
\end{abstract}

Keywords: Cellular structure; Trapezoidal beam; Elastic moduli; Shear modulus; Finite element, Crack

\section{Introduction}

Wing morphing can drastically improve the mechanical and aerodynamic performance of the aircraft [1-3]. Flexible skin is very important to design morphing structures. The study of cell structures for flexible skin is of practical importance and has been a subject of interest for engineers and researchers.

In the past few decades, all kinds of cellular structures with positive and negative Poisson's ratio have been proposed for flexible skins for its lightweight and high stiffness, such us conventional hexagonal honeycombs with positive Poisson's ratios [4-9] and negative positive Poisson's ratios [10-21]. However, nonzero Poisson's ratio can unavoidably limit their applications on one-dimensional deformations. So, a lot of cellular structures with zero or close to zero positive Poisson's ratios have been studied by researchers [22-26]. In the previous study, researchers employed the theoretical analysis, finite element methods, and experiments to study the elastic properties, including elastic moduli and shear moduli.

However, the flexible skins can inevitably contain cracks during service, which has bad effects on the mechanical properties of the flexible skins. However, there are few kinds of literature on the effects of the cracks on the mechanical properties of cellular structures. So, in this paper, the finite element method is used to study the elastic properties of a cracked cellular with close to zero positive Poisson's ratios proposed by the authors [26]. Some effective moduli are obtained in this study.

\section{Geometrical Model}

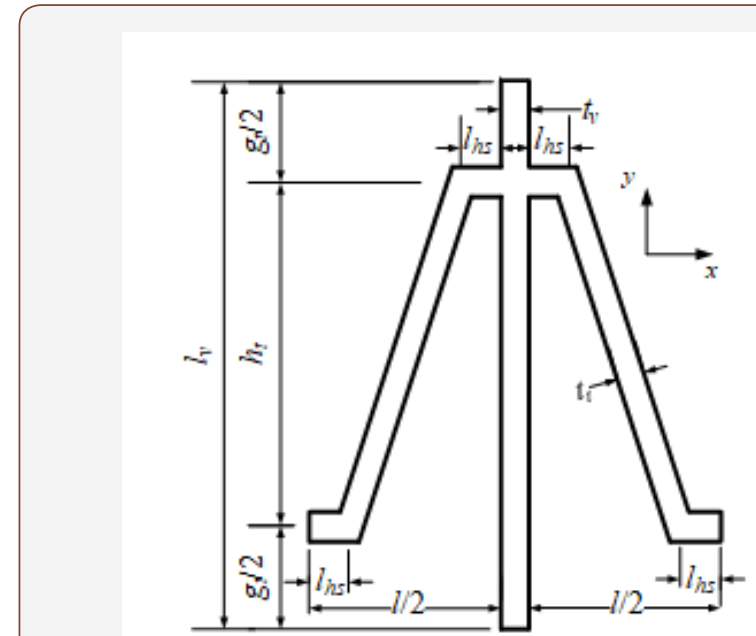

Figure 1: The unit cell of the structure.

Figure 1 shows the unit cell of the proposed structure. The unit cell possesses parallel aligned vertical beams and trapezoidal beams between the vertical beams. The detailed geometry of the unit cell 
can be determined by the following parameters in Table 1 . The following non-dimensional geometrical parameters are also defined to study the elastic properties of the structure: $h=h_{t} / l$ (height-tolength ratio of the trapezoidal beam), $t=t_{t} / l$ (thickness-to-length ratio of the trapezoidal beam), $g=g_{t} / l$ (spacing-to-length ratio of the trapezoidal beams), $\mu=l_{h s} / l$ (horizontal sub-beam proportion ratio along $\mathrm{x}$-direction), $\eta=t_{v} / t_{t}$ (vertical beam to trapezoidal beam thickness ratio ), $b=b_{t} / l$ (cell depth-to-length ratio).

Table 1: Detailed geometry parameters of the unit cell.

\begin{tabular}{|c|c|}
\hline \multicolumn{1}{|c|}{ Name } & Symbol \\
\hline Length in the x-direction of the trapezoidal beam & $h_{t}$ \\
\hline Height in the y-direction of the trapezoidal beam & $t_{t}$ \\
\hline The thickness of the trapezoidal beam & $l_{h s}$ \\
\hline Length in the x-direction of each horizontal sub-beam & $g_{t}$ \\
\hline Pacing in the y-direction between two adjacent trapezoidal beams & $t_{v}$ \\
\hline Is the thickness of the vertical beam & $l_{v}$ \\
\hline
\end{tabular}

Full-scale models of $20 \times 20$ unit cells with a central crack is shown in Figure 2. As shown in Figure 2, the length of the crack is $2 \mathrm{a}$, and the inclined angle of the crack is $\theta$.

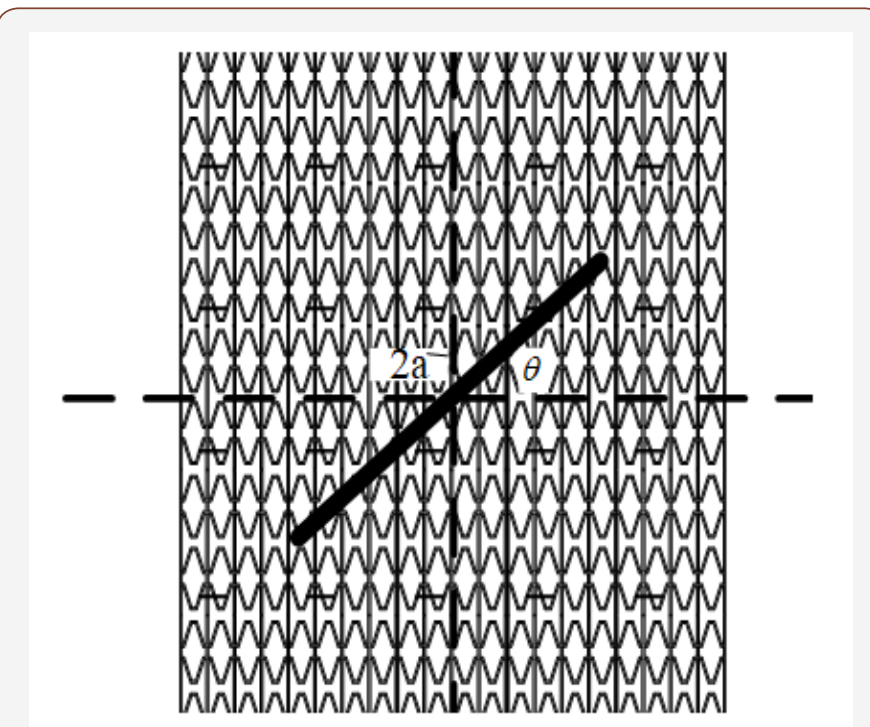

Figure 2: The geometry of the full-scale structure with a central crack.

\section{Finite Element Modeling}

A three-dimensional model is created in the commercial soft package ABAQUS. 8-node shell elements are used in this study. In this paper, the non-dimensional geometrical parameters were fixed as $h=1, t=0.1, g=1, \eta=1$. The non-dimensional equivalent elastic modulus in the x-direction, y-direction and shear modulus is defined as $E_{x} / E, E_{y} / E, G_{x y} / E$ respectively. The effects of the crack length and crack angle on the non-dimensional equivalent modulus are studied. The moduli $\mathrm{E}$ and $\mathrm{G}_{\mathrm{xy}}$ are then obtained as the ratios between the averaged stresses and the imposed strains. The homogenized stresses are calculated by averaging the reaction forces along the direction of the imposed displacement over the boundary. The boundary conditions are listed in Table 2.

Table 2: Boundary conditions on the FE models.

\begin{tabular}{|c|c|c|c|}
\hline Boundary & $\mathbf{E}_{\mathrm{x}}$ & $\mathbf{E}_{\mathrm{y}}$ & $\mathbf{G}_{\mathrm{xy}}$ \\
\hline Left Side & $u_{1}=u_{2}=u_{3}=0$ & Free & $u_{1}=u_{2}=u_{3}=0$ \\
\hline Right Side & $\begin{array}{c}u_{1}=\text { imposed } \\
u_{2}=u_{3}=0\end{array}$ & Free & $\begin{array}{c}u_{2}=\text { imposed } \\
u_{1}=u_{3}=0\end{array}$ \\
\hline Upside & Free & $\begin{array}{c}u_{2}=\text { imposed } \\
u_{1}=u_{3}=0\end{array}$ & Free \\
\hline Downside & Free & $u_{1}=u_{2}=u_{3}=0$ & Free \\
\hline
\end{tabular}

\section{Results and Discussion}

The typical deform shapes of the cracked structure are shown in Figure 3.

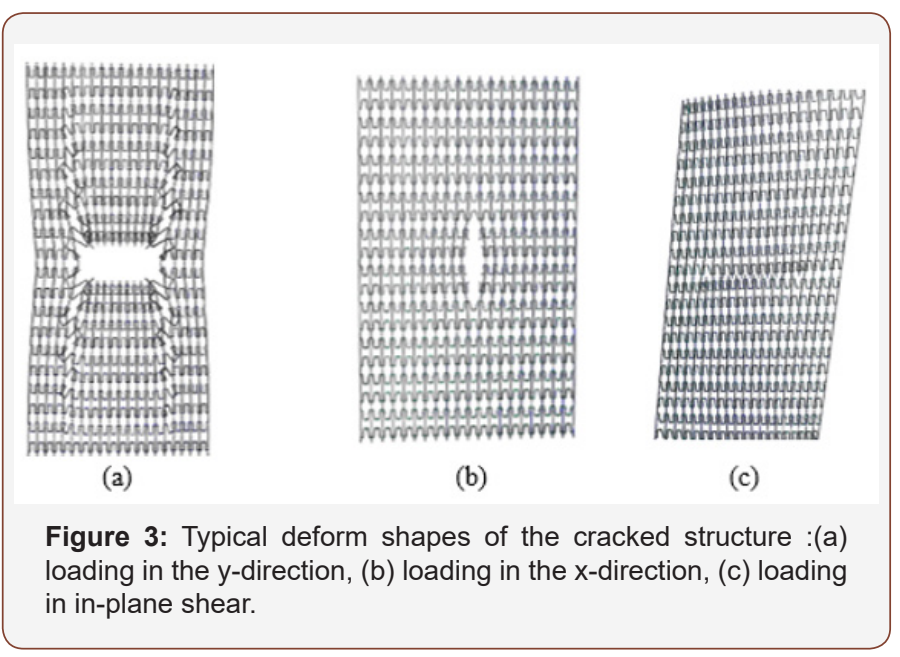


The effects of the crack length on the non-dimensional equivalent modulus

In this part, the inclined crack angle is fixed at $90^{\circ}$. The crack length ratio $a / W$ is selected to be $0.125,0.25,0.375,0.5,0.625$, where $\mathrm{W}$ is the half width of the structure. Figure 4 shows the effects of the crack length on the $E_{x} / E, E_{y} / E$ and $G_{x y} / E$.

As we can see from Figure 4, crack length has a great effect on the non-dimensional equivalent modulus. All three equivalent modulus decrease with the increase of the crack length.

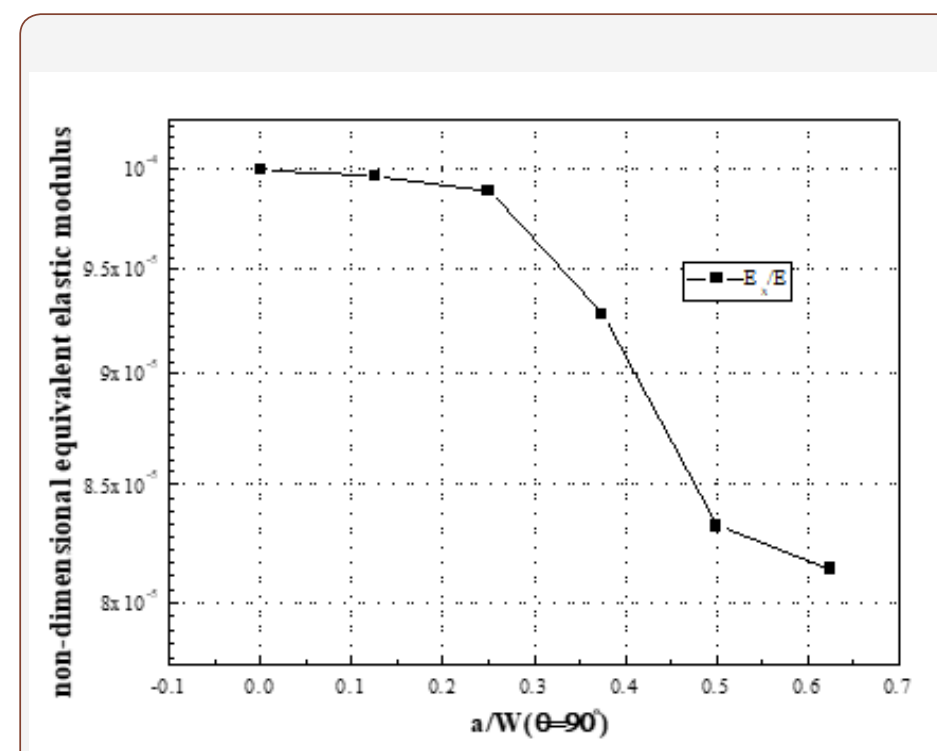

(a)

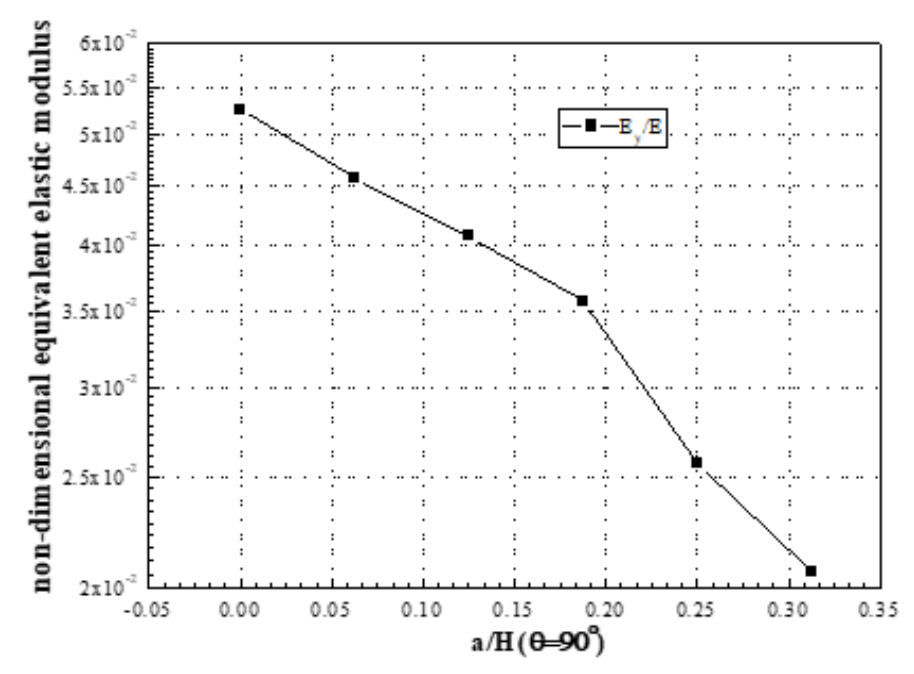

(b)

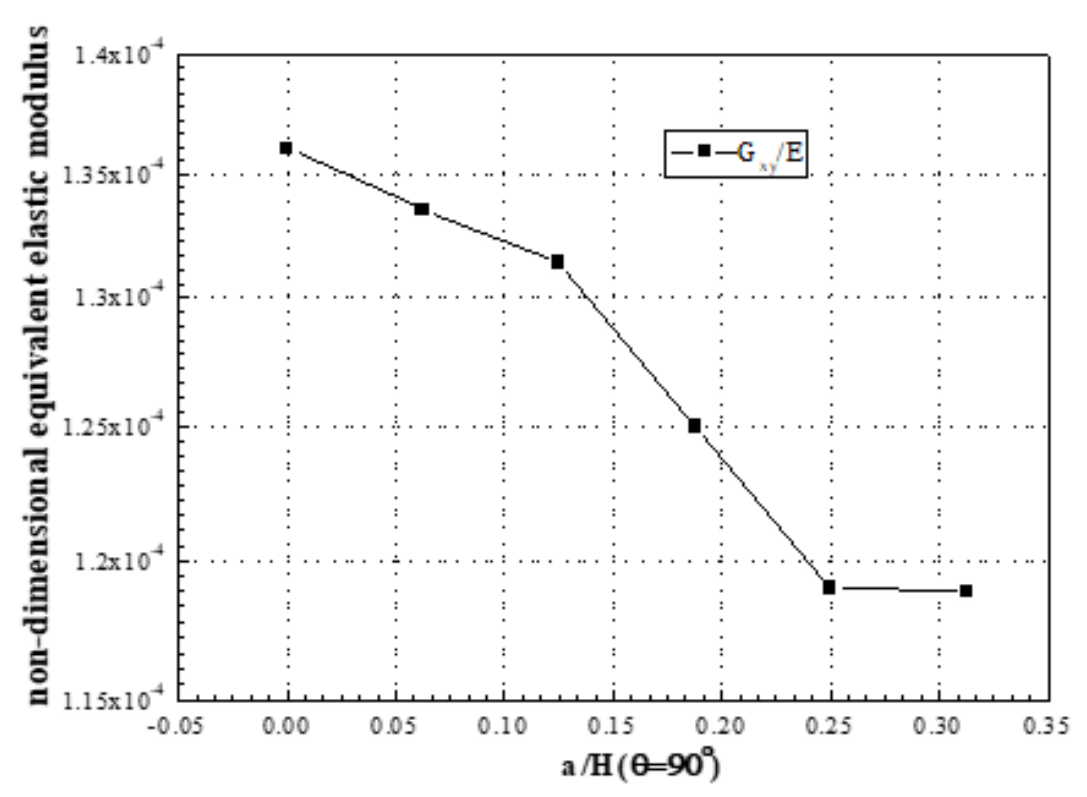

(c)

Figure 4: Effects of the crack length on the non-dimensional equivalent modulus: (a) $E_{x} / E$,(b) $E_{y} / E$,(c) $G_{x y} / E$

\section{The effects of the crack inclined angle on the non-} dimensional equivalent modulus

In this study, the crack length ratio $a / W$ is fixed at 0.5 . The inclined crack angle $\theta$ is selected to be $0^{\circ}, 15^{\circ}, 30^{\circ}, 45^{\circ}, 60^{\circ}, 75^{\circ}, 90^{\circ}$ . Figure 5 shows the effects of the crack inclined angle on the $E_{x} / E, E_{y} / E$ and $G_{x y} / E$.
It can be seen in Figure 5, $E_{x} / E$ decreases with the increase of the inclined angle of the crack while $E_{y} / E$ increases with the increase of the inclined angle of the crack. However, it is complicated for $G_{x y} / E . G_{x y} / E$ firstly, decreases with the increase of the inclined angle when $\theta$ it is less than $60^{\circ}$. When $\theta>60^{\circ} G_{x y} / E$ increases with the increase of the inclined angle. 


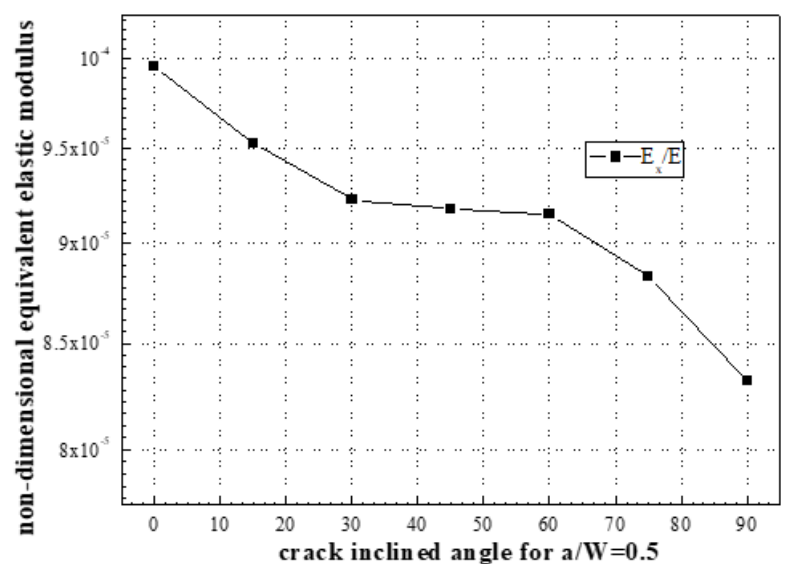

(a)

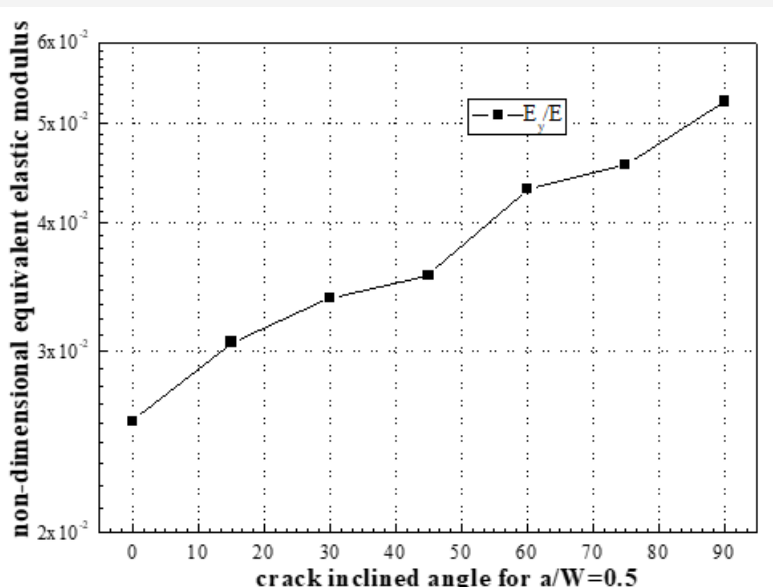

(b)

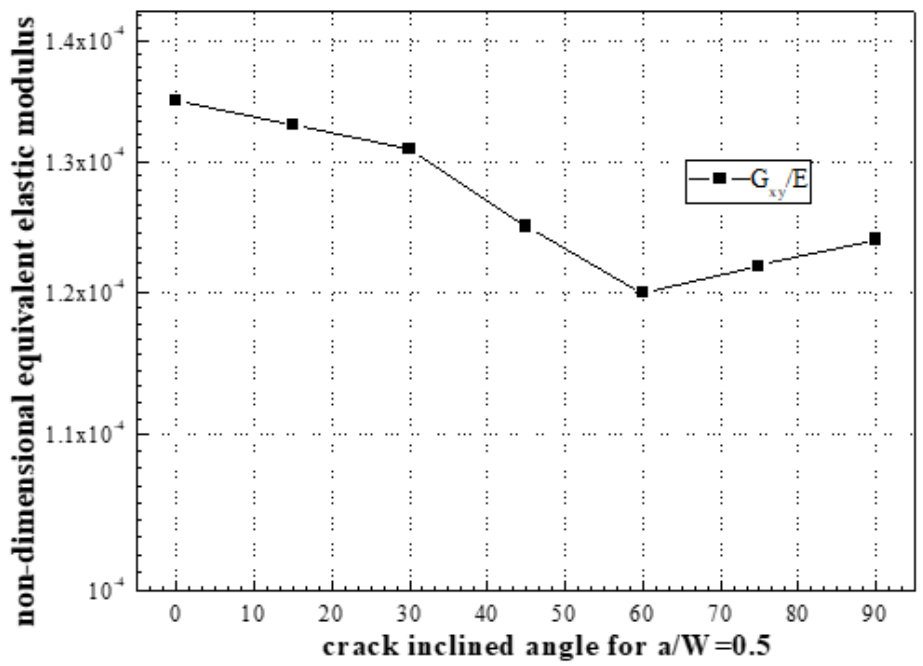

(c)

Figure 5: Effects of the crack inclined angle on the non-dimensional equivalent modulus: (a) $E_{x} / E$, (b) $E_{y} / E$,(c) $G_{x y} / E$

\section{Conclusion}

In this paper, the finite element method is used to study the elastic properties of a cracked cellular structure of close-to-zero Poisson's ratio with trapezoidal beams. The effects of the crack length and crack angle on the non-dimensional equivalent modulus, including elastic moduli, are analyzed. From the numerical example, we can see that the equivalent modulus decreases with the increase of the crack length, while the effect of the crack inclined angle on the equivalent modulus is complicated.

\section{Acknowledgment}

This work was supported by the National Natural Science Foundation of China [Grant number 51605140]; the Natural Science Foundation of Jiangsu Province [Grant number BK20150802]; the Fundamental Research Funds for the Central Universities [Grant number 2015B02914] and the innovation and strong school engineering fund of Guangdong Province (NO.2017KQNCX201) and Natural Science Foundation of Guangdong Province (No.2018A030313430).

\section{Conflict of Interest}

No conflict of interest.

\section{References}

1. Barbarino S, Bilgen O, Ajaj RM, Friswell MI, Inman DJ (2011) Journal of Intelligent Material Systems and Structures 22: 823.

2. Sun J, Guan Q Liu Y, Leng J (2016) Journal of Intelligent Material Systems and Structures 27: 2289.

3. Daynes S, Weaver PM, Bae J (2011) The International Society for Optical Engineering 7979: 843

4. Gibson LJ, Ashby MF (1997) Cambridge University Press.

5. Masters I, Evans K (1996) Compos Struct 35: 403.

6. Bitzer T (1997) Springer Science \& Business Media.

7. Gibson L, Ashby M, Schajer G, Robertson C (1982) The Royal Society 25: 42 .

8. Grediac M (1993) Int J Solids Struct 30: 1777.

9. El-Sayed FA, Jones R, Burgess I (1979) Composites10: 209.

10. Almgren RF (1985) J East 15: 427.

11. Scarpa F, Burriesci G, Smith F, Chambers B (2003) Aeronaut J 107: 175. 
12. Scarpa F, Tomlinson G (2000) J Sound Vib 230: 45.

13. Lira C, Innocenti P, Scarpa F (2009) Compos Struct 90: 314.

14. Murray GJ, Gandhi F (2013) J Intell Mater Syst Struct 104: 5389.

15. Chen Y, Scarpa F, Liu Y, Leng J (2013) Int J Solids Struct 50: 996.

16. Bornengo D, Scarpa F, Remillard C (2005) J Aerosp Eng 219: 185.

17. Prall D, Lakes RS (1997) Int J Mech 39: 305.

18. Lorato A, Innocenti P, Scarpa F, Alderson A, Alderson K, et al. (2010) Compos Sci Technol 70: 1057.

19. Theocaris P, Stavroulakis G, Panagiotopoulos P (1997) Arch Appl Mech 67: 274 .
20. Alderson A, Alderson K (2007) J Aerosp Eng 221: 565.

21. Larsen UD, Sigmund O, Bouwsta S (1997) J Microelectromech Syst 6: 99.

22. Olympia KR, Gandhi F (2010) Journal of Intelligent Material Systems and Structure 21: 1737.

23. Bubert EA, Woods BK, Lee K, Kothera CS, Wereley NM (2010) Journal of Intelligent Material Systems and Structures 21: 1699.

24. Weidong L, Hongda L, Jiang Z (2017) Composite Structure s 180: 251.

25. Xiaobo Gong, Jian Huang, Fabrizio Scarpa, Yanju Liu, Jinsong Leng (2015) Composite Structures 134: 384.

26. Weidong Liu, Honglin Li, Jing Zhang, Hongda Li (2018) Aerospace Science and Technology 75: 315. 